\title{
Será que a temática da caça no Brasil tem recebido a atenção necessária?
}

\author{
Felipe Santana Machado ${ }^{1}$ \\ João Carlos Costa Guimarães² \\ Luís Antônio Coimbra Borges 3 \\ José Luiz Pereira de Rezende 4 \\ Bruno Senna Corrêa ${ }^{5}$
}

\section{Resumo}

A região intertropical brasileira apresenta elevada diversidade e está ameaçada, inclusive pela pressão de caça, que vem reduzindo a abundância e a diversidade de espécies. A caça é proibida, mas há uma pressão pela sua legalização em situações especiais. As denominações de algumas Unidades de Conservação fazem referência direta à fauna, como a Reserva de Fauna e Refúgio da Vida Silvestre. Paradoxalmente, a legislação proíbe a caça profissional e ao mesmo tempo estimula a criação de grupos de caça amadores, o que torna confusa a compreensão de determinados artigos. Diante dessa situação, o presente estudo visa analisar criticamente a temática da caça na legislação pertinente, abordando a cronologia das principais leis referentes ao manejo da fauna, a influência da pressão de caça sobre a diversidade de espécies nativas, e, por fim, a relação das Unidades de Conservação e a exploração dos recursos faunísticos.

Palavras-chave: Legislação. Manejo da fauna. Unidade de Conservação.

\section{Introdução}

A região intertropical brasileira apresenta elevada diversidade de espécies e alta taxa de endemismos (MYERS et al., 2000), entretanto diversos processos interagem ameaçando a fauna silvestre. Os processos mais elencados por especialistas são o desmatamento e a fragmentação (DIXO et al., 2009; LAURANCE et al., 2011). Esses processos atuam sinergicamente - originando por exemplo a caça predatória - e conduzem a um processo acelerado de extinção. A pressão de caça é uma das atividades que vem reduzindo a abundância e a diversidade de espécies (CULLEN JR.; BODMER; VALADARES-PADUA, 2000; PERES, 2000). Apesar de ser proibida no Brasil (BRASIL, 1967; BRASIL, 1998), alguns grupos querem legalizar a caça em situações como controle populacional, alimentação de comunidades tradicionais e fins esportivos (ARCO, 2012; MIRANDA, 2011).

Ao tentar unir o uso dos recursos faunísticos à preservação, o governo brasileiro utiliza como ferramenta conciliadora a legislação pertinente, que se mostra muitas vezes dual por proibir a caça e ao mesmo tempo liberá-la em situações especiais (BRASIL, 1967; BRASIL, 1998). Entretanto, entende-se que a sua liberação fica condicionada a uma série de trabalhos que visem: compreender

Departamento de Ciências Florestais DCF - Universidade Federal de Lavras UFLA, epilefsama@hotmail.com

Departamento de Ciências Florestais DCF - Universidade Federal de Lavras UFLA, joão.guimaraes77@gmail.com

Departamento de Ciências Florestais DCF - Universidade Federal de Lavras UFLA, luis.borges@dcf.ufla.br

Departamento de Ciências Florestais DCF - Universidade Federal de Lavras UFLA, jlprezen@ufla.br

Centro Federal de Educação Tecnológica de Minas Gerais CEFET/MG, bruno.senna@gmail.com 
a dinâmica populacional das espécies que por ventura terão sua caça liberada, aspectos culturais, e como o governo fiscalizará as ações pós-liberação.

Assim sendo, o presente trabalho tem por objetivo discutir questões relacionadas à caça no Brasil em três tópicos: "A problemática da caça: contextualização", "Cronologia e importância das principais leis referentes ao manejo da fauna", e "As Unidades de Conservação".

\section{Material e Métodos}

Este trabalho foi desenvolvido por meio de uma análise crítica dos aspectos jurídicos. Buscou-se considerar as principais publicações, que foram utilizadas para o embasamento, bem como foram analisados os principais pontos conflitantes. Para isso, foi realizado um inventário da legislação da fauna com o intuito de demonstrar quantas normas jurídicas se aplicam ao tema, como estas afetam (direta ou indiretamente) a fauna e quais os órgãos de promulgação. Essas informações foram organizadas em gráficos circulares e de barras.

\section{Resultados e Discussão}

\subsection{A problemática da caça: contextualização}

A pressão da caça e a sua associação com outros fatores geram uma ação sinérgica que culmina em processos de extinção (PRIMACK; RODRIGUES, 2001). Apesar dessa particularidade, a caça ainda é amplamente realizada e não somente para a comercialização de carne e peles, mas de subprodutos que são direcionados para diversos objetivos. Alguns artigos científicos mencionam essa comercialização e esses custos. Romero-Muñoz e Pérez-Zubieta (2008) fazem uma avaliação preliminar dos recursos faunísticos comercializados no mercado "De La Pampa", em Cochabamba, na Bolívia. Segundo esses autores, foram encontrados indivíduos (vivos e mortos) pertencentes a três ordens (Artiodactila, Cingulata e Chiroptera) em um período amostral curto, de 15 de abril a 2 de juIho. Esses "produtos" foram separados em cinco categorias de uso: ornamental, amuleto, medicinal, doméstico e ritualístico, os quais eram comercializados livremente e constantemente repostos pela sua demanda.

O preço de comércio varia entre as formas exploratórias. Romero-Muñoz e Pérez-Zubieta (2008) comentam que o valor total estimado era de US\$1.500,00. Apesar do trabalho de Romero-Muñoz e Pérez-Zubieta (2008) não ter sua área de estudo no Brasil, sabe-se que muitos são os produtos e subprodutos de origem animal, advindos de feiras livres no Brasil e comercializados principalmente das regiões Norte e Nordeste.

Os produtos gerados pela caça podem ser categorizados em três diferentes objetivos de aquisição: subsistência, esportiva ou comercial ilegal (tráfico).

A caça de subsistência tem por conceito utilizar os recursos de origem animal apenas para a manutenção das atividades normais do organismo (DELGADO, 2005), sem o objetivo de comercialização. O senso comum veicula que esse tipo de relação entre o homem e o meio ambiente é a mais ecologicamente equilibrada, entretanto alguns trabalhos têm demonstrado que esse tipo de exploração pode conter riscos, pois seus efeitos são difíceis de serem observados em escalas de espaço e indetectáveis em pequena escala espacial (PERES, 2000).

Existe uma preferência por cervídeos, antas, cutias, pacas, porcos do mato, tatus, macacos (PERES, 2000; ROSAS; DRUMOND, 2007; PEZZUTI; CHAVES, 2009), quatis, jacus, perdizes 
(CULLEN JR.; BODMER; VALADARES-PADUA, 2000) e quelônios (PEZZUTI; CHAVES, 2009). A preferência por esses grandes grupos está relacionada a uma série de fatores, dentre eles podemos citar a sua fácil aquisição, preferência regional por determinados tipos de carnes, relações culturais e facilidades no abate. A caça de subsistência desses animais de médio e grande porte resulta na redução do tamanho populacional, consequentemente guiando a um vórtex de extinção, pois alguns destes animais têm longos ciclos reprodutivos e de gestação, baixa fecundidade e uma menor prole (PERES, 2000).

Reclamações sobre a redução da caça são constantes entre alguns povos indígenas (PEZZUTI; CHAVES, 2009) e a migração é fato comum, onde se percebe que aldeias recém instaladas têm maiores recursos de caça do que as mais antigas (PEZZUTI; CHAVES, 2009).

A caça esportiva está relacionada principalmente à conservação de tradições e culturas. Regiões do "Velho Mundo" praticam a caça esportiva há centenas de anos e ainda permanecem mantendo suas tradições. Em todo o território brasileiro, a caça profissional é uma prática proibida, entretanto o Rio Grande do Sul era o único estado que, em 2002, autorizou a caça amadora de algumas espécies: Nothura maculosa (perdiz), Dendrocygna viduata (marreca-piadeira), Lepus capensis (lebre europeia), Columba picazuro (pombão), Zenaida auriculata (pomba-de-bando), Myiopsitta monachus (caturrita) e Agelaius ruficapillus (Garibaldi). Em 2008, houve novamente a proibição da caça no Rio Grande do Sul por meio de uma decisão judicial movida pela Associação Civil União pela Vida (TRF, 2008).

Apesar da caça profissional ser proibida no Brasil, o artigo $6^{\circ}$ da Lei $n^{0} 5.197$, de 3 de janeiro de 1967, determina que o poder público "estimulará a formação e o funcionamento de clubes e sociedades amadoristas de caça e de tiro ao voo objetivando alcançar o espírito associativista para a prática desse esporte" (BRASIL, 1967). Entende-se como contraditória a ideia de proibição em um artigo e a estimulação de criação de grupos de caça amadorista em outro, uma vez que os órgãos competentes acumulam atividades e a fiscalização da atividade de caça se torna inviável.

O tráfico de animais silvestres é um tópico a ser abordado separadamente, pois é um problema enfrentado pelo Brasil e relatos têm sido frequentemente reportados em artigos científicos (e g. VIDOLIN et al., 2004; BARBOSA; NOBREGA; ALVES, 2010). Esse tráfico é uma das três maiores atividades ilegais do mundo. No Brasil, ele movimenta aproximadamente 1,5 bilhões de dólares por ano e retira da natureza em média de 38 milhões de animais por ano. Desse montante final, estima-se que somente um a cada 10 indivíduos chega ao comprador final e os outros nove morrem durante a captura ou transporte (BORGES; RESENDE, 2007).

A forma mais efetiva para prevenir o comércio ilegal é a fiscalização, principalmente no ambiente, nas rotas de transporte e nos locais de venda (PAGANO et al., 2009; BARBOSA; NOBREGA; ALVES, 2010). Alguns projetos da polícia ambiental relatam o escoamento dos animais traficados pelas principais rodovias federais e sugerem aumento da fiscalização (PAGANO et al., 2009). Fato também observado por Borges et al. (2006), que relaciona o aumento das apreensões de animais silvestres na região de Juiz de Fora-MG pela Polícia Militar do Meio Ambiente ao aumento da fiscalização em 1998 e 1999.

A fiscalização em ambientes naturais é outro aspecto que precisa ser revisto, pois além do distúrbio causado pela extração da fauna silvestre, alguns grupos de espécies, como os répteis, mamíferos e principalmente as aves, são muito visados pelos contrabandistas (VIDOLIN et al., 2004). A apreensão desses animais é constante e a forma correta de manejar a fauna silvestre apreendida é comentada por esses mesmos autores. Os animais apreendidos podem causar uma série de danos, por isso estudos prévios precisam ser realizados com o intuito de verificar a capacidade de suporte do ambiente e principalmente da saúde do indivíduo capturado, evitando que o mesmo sirva de veiculador de doenças. 


\subsection{Cronologia e importância das principais leis referentes ao manejo da fauna}

Os decretos e decretos-legislativos foram as normas com maior representatividade, com 70 dos 275 documentos inventariados (Figura 1), mas somente 75 (27\%) do total final afetam diretamente a fauna (Figura 2).

Figura 1. Número de documentos inventariados até junho de 2012 e seus respectivos órgãos de promulgação. Lavras, 2013.

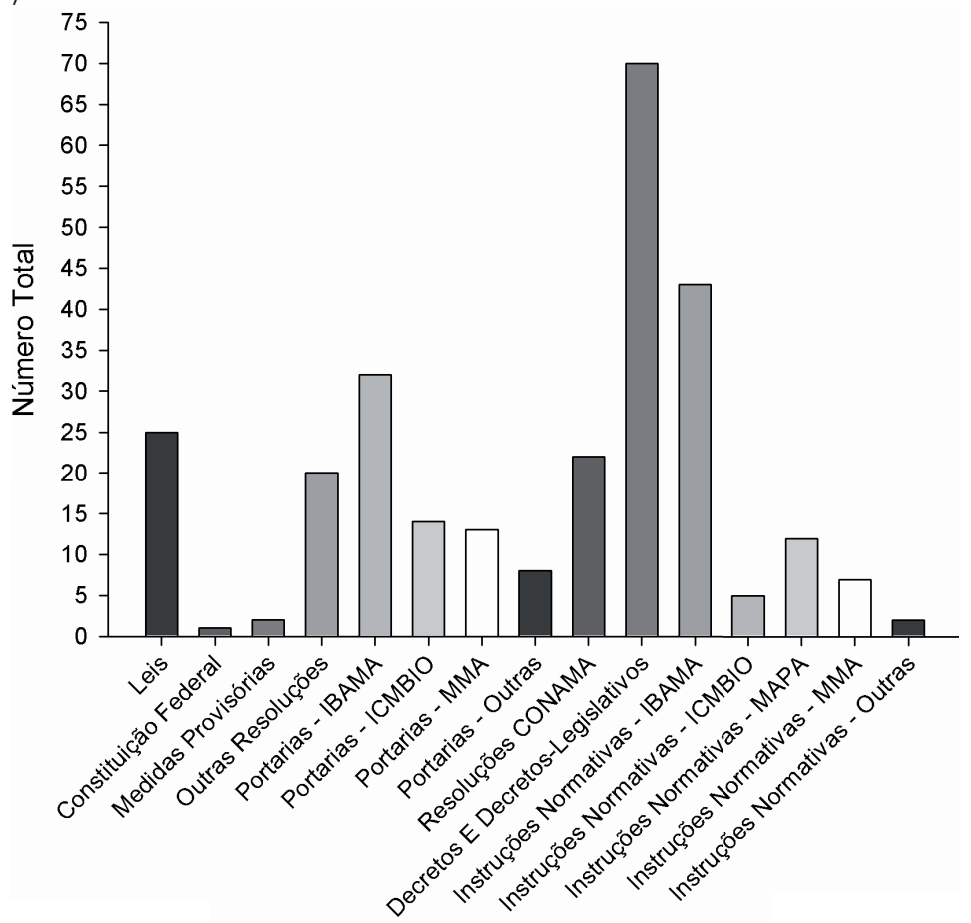

Fonte: Elaboração própria.

Entender os principais aspectos legislativos do manejo da fauna ajuda a compreender o real valor deste recurso no Brasil e fomenta a pesquisa na tentativa de alcançar um manejo adequado e sustentável. Os aspectos abordados a posteriori referem-se somente àqueles considerados pertinentes e importantes sobre a temática.

As normas jurídicas relacionadas à fauna apresentam-se desde a década de 1930, principalmente com o Decreto Federal $n^{0}$ 24.645, de 10 de julho de 1934, que estabeleceu medidas de proteção aos animais (BRASIL, 1934). Berti e Marx Neto (2007) comentam a existência de problemas desde o século XIX relacionados à dominação e violência dos homens sobre os animais, e que a partir de uma iniciativa da União Internacional de Proteção aos Animais (UIPA), ao importar a legislação vigente na Europa (DIAS, 2007), houve o início da regulamentação para a proteção da fauna. 0 ponto mais forte desse decreto é a definição em seu art. $3^{\circ}$ dos principais tipos de maus tratos. Entretanto, percebe-se intrinsecamente o caráter de proteção aos animais prestadores de serviços à população urbana ou rural, sendo que, por exemplo, em alguns de seus artigos, há restrições acerca dos transportes de tração animal (art. $4^{\circ}$ ao $7^{\circ}$ ). Até esse momento, a legislação brasileira considerava os delitos contra a fauna como crimes contra a propriedade, sendo os animais avaliados simplesmente com base em valores de mercado. 
Figura 2. Porcentagem de documentos inventariados até junho de 2012 que afetam ou não diretamente a fauna. Lavras, 2013.

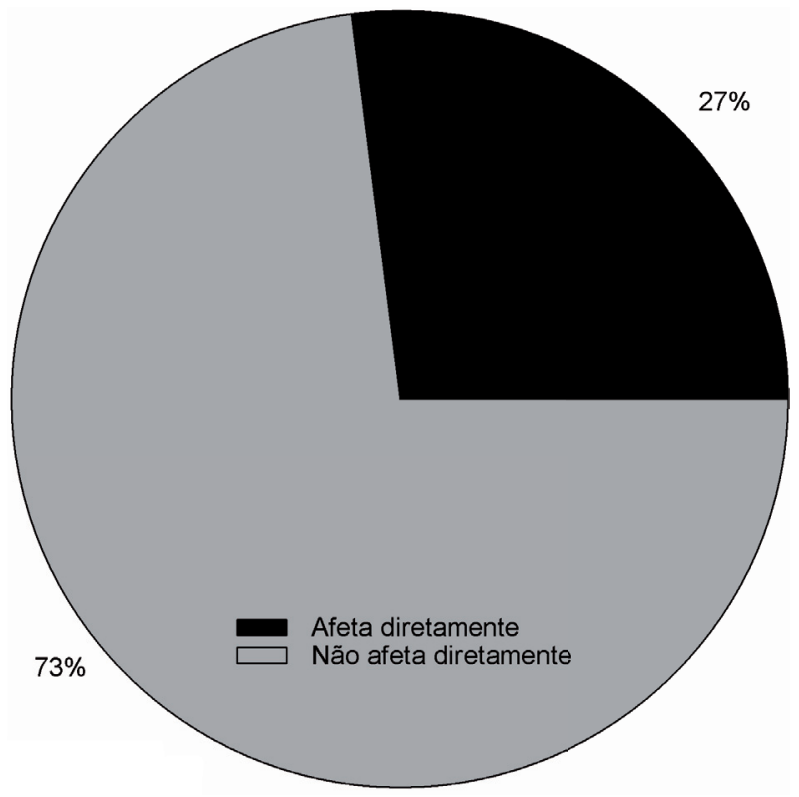

Fonte: Elaboração própria.

Em 1967, houve a instituição da Lei no 5.197/1967 de Proteção à Fauna (BRASIL, 1967). A partir desse momento, a fauna silvestre passou a ser considerada propriedade do estado. Um grande avanço foi obtido, pois além da preservação, houve uma série de restrições, tais como:

a) proibição da caça e exploração comercial ilegal da fauna silvestre;

b) impedimento da introdução de espécies exóticas;

c) restrições para coleta de material biológico de origem animal por cientistas;

d) proibição de produtos brutos de origem animal;

e) restrições ao transporte.

Lourival e Fonseca (1997) comentam que essa lei de 1967 causou muita controvérsia, pois houve restrições às coletas para pesquisas científicas enquanto que pouco se fez a respeito da caça predatória ilegal e do contrabando de produtos de origem animal. Os experimentos práticos sobre a conservação e manejo tiveram um retrocesso e as pesquisas foram desestimuladas. Apesar disso, essa lei não pode ser considerada como falha ou inócua, pois os problemas não estão relacionados às ações punitivas dos crimes contra a fauna, mas sim à demora das ações de fiscalização, que apresentava e ainda apresenta infraestrutura deficiente (BUCCl et al., 1992). A questão da fiscalização ainda é um problema, pois quando se observa a relação entre o número de profissionais e a área a ser fiscalizada, tem-se como situação menos crítica a região Sudeste, com aproximadamente um funcionário para cada 3.751,86 ha; no oposto está a região Norte, onde cada funcionário é responsável por 314.761,63 ha (SANTOS, 2010). Bucci et al. (1992) ainda comentam que a falta de estrutura para os agentes da fiscalização propicia e incentiva a transgressão da lei.

A Constituição Federal menciona sucintamente em seu artigo 225 (BRASIL, 1988) que cada estado deve definir territórios a serem protegidos com o objetivo de estudar e preservar a fauna e a flora, sendo utilizado o termo "Unidades de Conservação". Bucci et al. (1992) comentam que houve um grande avanço na legislação ambiental com a presença de um capítulo específico sobre o meio ambiente, influência do Código Florestal de 1965, Lei nº 7.802, de 11 de julho de 1989 (BRASIL, 
1965). Após a aprovação da Constituição Federal e seu artigo específico referente à fauna, os estados e municípios contemplaram a defesa animal em suas constituições e leis orgânicas, respectivamente. Portanto, a proteção animal tornou-se uma garantia constitucional (DIAS, 2007).

Passados onze anos da Lei 5.197/67, a UNESCO publicou a Declaração Universal dos Direitos dos Animais (UNESCO, 1978). A declaração aborda tópicos de maneira clara e ampla, e apresenta a idéia do bem estar do animal vivo e do respeito ao animal morto.

Em fevereiro de 1989, houve a criação do Instituto Brasileiro do Meio Ambiente e dos Recursos Naturais Renováveis (IBAMA - Brasil, 1989). O IBAMA assumiu esse papel liberando portarias e instruções normativas que "definem, regulamentam, organizam, autorizam, exercem e controlam" todas as atividades relacionadas às políticas nacionais de meio ambiente. No início da década de 1990, uma série de portarias foi criada. A primeira delas foi a Portaria n 332/1990 sobre a licença para coleta de material zoológico (IBAMA, 1990). Segundo essa portaria, as licenças para fins didático-científicas poderiam ser concedidas a profissionais qualificados, pertencentes a instituições científicas brasileiras públicas e privadas credenciadas. A criação dessa portaria deu início ao processo de controle de licenças de coleta do material zoológico, que culminou no Sistema de Autorização e Informação em Biodiversidade, o SISBio (IBAMA, 2007), metodologia de referência, pois acelerou a emissão de licenças de coleta e gerou um banco de dados sobre a área de ocorrência das espécies. $A$ representatividade do IBAMA é demonstrada na porcentagem de normas promulgadas inseridas nos $27 \%$ que "afetam diretamente a fauna" (Figura 2). Entre instruções normativas e portarias somou-se $36 \%$ do total de normas (Figura 3).

Figura 3. Porcentagem de documentos inventariados até junho de 2012 inseridos nos $27 \%$ que afetam diretamente a fauna separados por órgãos governamentais de promulgação. Lavras, 2013.

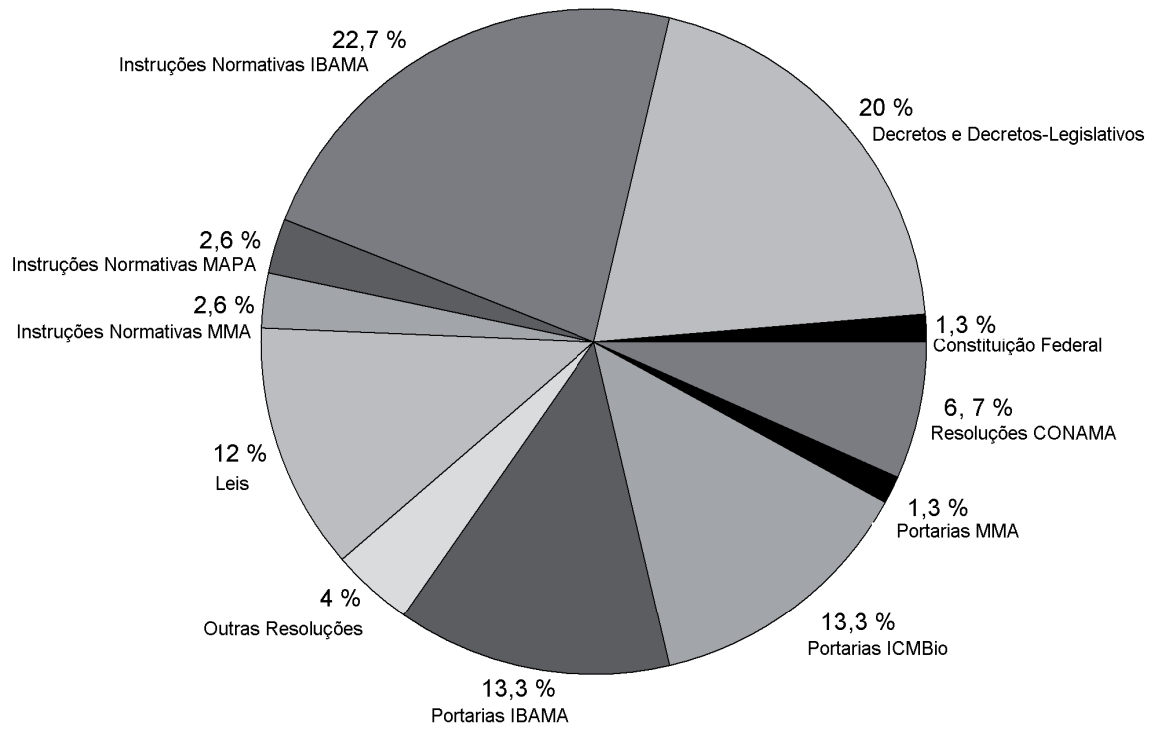

Fonte: Elaboração própria.

Em 1998, retornam as leis presidenciais com a sanção da Nova Lei de Crimes Ambientais, Lei $n^{0}$ 9.605, de 12 de fevereiro de 1998, que atualiza conceitos e menciona os tipos de crimes e suas respectivas penas e multas, ponto de destaque da lei (BRASIL, 1998). Complementarmente, o Decreto $n^{\circ}$ 6.514, de 22 de julho de 2008 especifica dispõe as sanções aos comportamentos e atividades danosas (BRASIL, 2008), sendo que nesse decreto há a valoração das perdas. Com a promulgação dessas leis, houve um avanço na legislação referente à fauna, sendo que os crimes 
que aconteciam antes dessas leis eram tratados como contravenções, não havendo punições em sua maioria. Dias (2007) comenta que para que houvesse a inclusão da proteção animal na Lei de Crimes Ambientais fora necessária uma militância iniciada em 1983 pela Liga de Prevenção da Crueldade contra o Animal (LPCA). Atualmente, os atentados contra fauna são punidos, entretanto somente os crimes que afetam funções ecológicas são punidos de forma imediata.

De uma forma global, a legislação Brasileira sobre o manejo da fauna consegue abordar diferentes temáticas, mas o tempo entre as promulgações das principais leis é demasiadamente longo, compreendendo 33 anos entre as leis 24.645/34 e a 5.197/67, além dos anos de defasagem até os tempos atuais. Esses problemas e atrasos referentes à legislação da fauna são interpretados como um retrocesso naquilo que se refere à possibilidade de liberação da caça no Brasil, pois algumas decisões são tomadas de forma retrógrada, tendo em vista que algumas leis precisam ser constantemente re-examinadas e atualizadas (CARDOSO, 2007).

\subsection{As Unidades de Conservação}

A pesquisa científica sobre dinâmica populacional de espécies que poderiam ter sua caça liberada no Brasil é ainda muito incipiente. Conhecer as taxas migratórias, a natalidade e a mortalidade torna-se essencial para uma tomada de decisões. Para exemplificar essa situação, basta observar os trabalhos realizados com animais de médio e grande porte no Brasil. A grande maioria desses trabalhos descreve a composição da comunidade e menciona as informações sobre a abundância de forma simplificada. A maior parte das pesquisas utiliza metodologias menos onerosas e, consequentemente, simplificadas. O fato é que nem toda pesquisa científica irá resguardar a diversidade encontrada em todo território nacional. Mesmo assim, no Brasil existem algumas ferramentas efetivas de preservação da biodiversidade. Uma delas é a utilização de Unidades de Conservação (UC). Para isso foi sancionado o Sistema Nacional de Unidades de Conservação (SNUC), Lei no 9.985, de 18 de julho de 2000, (BRASIL, 2000), que ordena critérios para criar, implantar e gerir áreas protegidas. As UCs são divididas em dois grupos distintos:

a) Unidades de Proteção Integral;

b) Unidades de Uso Sustentável.

As UCs de Proteção Integral têm o intuito de preservar a natureza em todas as suas formas e as de Uso Sustentável tentam conciliar a conservação e o uso sustentável dos recursos naturais. Com esses conjuntos, o Estado, além de propiciar proteção, possibilita a utilização de recursos naturais em consonância com a preservação.

As UCs que fazem referência direta à fauna são os Refúgios de Vida Silvestre e as Reservas de Fauna. Não existe algum tipo de menção que possibilite a caça controlada ou o manejo dos recursos faunísticos. Os Refúgios de Vida Silvestre fazem parte das UCs de proteção integral, pois o seu objetivo está intrinsecamente relacionado à proteção de "ambientes naturais onde se asseguram condições para a existência ou reprodução de espécies ou comunidades da flora local e da fauna residente ou migratória" (BRASIL, 2000).

As Reservas de Fauna (REFAU) fazem parte do conjunto de UCs de Uso Sustentável e são adequadas para propostas que objetivam desenvolver o manejo econômico sustentável dos recursos faunísticos. É uma categoria de UC de posse e domínio público, aberto para visitação pública, e os proveitos das pesquisas realizadas nessa reserva devem ser direcionados à população. Contudo, os incisos III e IV da Lei no 9.985/2000 denotam um caráter restritivo, uma vez que os tipos de caça amadorística ou profissional são proibidos e a comercialização dos produtos das pesquisas científicas deveria obedecer a leis e regulamentos sobre a fauna (BRASIL, 2000). Além do artigo que restringe a utilização dos recursos nas REFAU, as leis 5.197/67 e 9.605/98 proíbem a caça claramente. Uma das alternativas para evitar problemas entre as duas linhas distintas de pensamento é o aumento do 
número de estudos que servirão de subsídios para a elaboração de uma proposta que vise à exploração dos recursos aliados à conservação.

No Brasil, foi instituída somente uma REFAU, a Costeira de Tibau do Sul, e existe uma proposta para criar mais uma UC, a REFAU Baía da Babitonga. A REFAU em Tibau do Sul-RN é uma UC municipal criada em 2006 que abrange $3.536 \mathrm{~km}^{2}$ de faixas costeiras e litorâneas do município. Os principais objetivos da criação da REFAU foi a preservação das espécies da fauna marina e o controle do manejo de pesca (TIBAU DO SUL, 2006). Entende-se que a criação da REFAU atende aos preceitos do SNUC, pois os incisos III e V (Decreto 14/2006, art. $3^{\circ}$ ) abordam a possibilidade de manejo econômico dos recursos faunísticos desde que "compatibilizem as atividades através do plano de manejo" e que "sejam estabelecidos mecanismos que viabilizem o custeio das atividades destinadas ao controle e monitoramento". Esses incisos são considerados imprescindíveis para efetivar trabalhos que possam subsidiar e embasar o manejo econômico sustentável dos recursos faunísticos.

A Baía de Babitonga está localizada no litoral norte de Santa Catarina e possui em seu entorno as cidades de Joinville e São Francisco do Sul, apresentando uma área de $130 \mathrm{~km}^{2}$. Os principais motivadores da construção dessa reserva são:

a) a preservação de algumas espécies (Sotalia guianensis, Pontoporia blainvillei, Ucides cordatus e Epinephelus itajara);

b) a utilização de recursos pesqueiros;

c) a proteção do sistema de mangues (IBAMA, 2007).

A proposta de criação de uma UC é uma ferramenta adequada para preservar espécies (Castro et al., 2008) consideradas carismáticas (aquáticas ou terrestres) e de áreas com um ecossistema atípico e único.

Poucas UCs mencionam diretamente a fauna e há problemas em sua instalação devido a confusões no entendimento de seus objetivos, portanto estes precisam ser mais bem pensados. Entretanto, uma situação precisa ser levada em consideração: uma área preservada que esteja circundada por uma matriz inóspita ou que não propicie a ligação entre subpopulações pode gerar isolamento de indivíduos, impossibilitando fluxo gênico, migrações e direcionando a extinção de espécies em uma escala de tempo maior. Portanto, uma política mais eficiente de manutenção das subpopulações relictuais deve ser efetivada para que estudos mais profundos sobre a fauna possam gerar o conhecimento científico que embase uma possível liberação da caça no Brasil.

\section{Considerações finais}

O Brasil apresenta uma biodiversidade de destaque no contexto mundial e a utilização dos recursos faunísticos ainda é uma questão a ser discutida no meio acadêmico e nas esferas governamentais. A legislação brasileira referente ao manejo da fauna consegue abordar aspectos em diferentes temáticas, entretanto o tempo entre as promulgações das leis é demasiadamente longo e isso faz com que algumas decisões sejam tomadas com atraso. O Brasil tem trazido timidamente a questão da caça como forma de uso dos recursos faunísticos, a sua regulamentação não foi efetivada, a discussão é incipiente, e a pesquisa que poderia subsidiar a definição de critérios técnico-científicos para a utilização dos recursos faunísticos precisa ser mais bem trabalhada e o seu número aumentado. Ainda assim, a possibilidade de liberar ou não a caça exige extrema cautela, uma vez que objetivos conservacionistas e preservacionistas são secundários nesse estilo de vida capitalista vigente. 


\section{Has the theme of hunting in Brazil had the necessary attention?}

\section{Abstract}

Brazilian intertropical region shows high diversity, but it is threatened by a number of factors, including hunting pressure, which has reduced the abundance and diversity of species in different areas of Brazil. Hunting is prohibited in Brazil there is a push for its legalization in special situations. The names of some protected areas make direct reference to the fauna, such as the Fauna Reserve and Wildlife Refuge. Paradoxically, the law prohibits professional hunting and at the same time stimulates the creation of amateur hunting groups, which confuses the understanding of certain articles. Given this situation, the present study aims to critically analyze the theme of hunting in the relevant legislation, addressing the chronology of major laws pertaining to wildlife management, the influence of hunting pressure on the diversity of native species, and finally, the relationship of Conservation Units and exploitation of wildlife resources.

Keywords: Legislation. Wildlife management. Conservation Unit.

\section{Referências bibliográficas}

ARCO. Pesquisa sobre a liberação da caça no Brasil. 2012. Disponível em: <http://arcobrasil. forumeiros.com/t2804-voce-e-a-favor-da-liberacao-da-caca-no-brasil-porque $>$. Acesso em: 30 mar. 2012.

BARBOSA, J. A. A.; NOBREGA, V. A.; ALVES, R. R. N. Aspecto da caça e comércio ilegal da avifauna silvestre por populações tradicionais do semi-árido paraibano. Revista de Biologia e Ciências da Terra, v. 10, n. 2, p. 39-49, 2010.

BERTI, S. M.; MARX NETO, E. A. Proteção Jurídica dos Animais. Revista Brasileira de Direito Animal, v. 2, n. 2, p. 107-113, 2007.

BORGES, R. C. et al. Diagnóstico da fauna silvestre apreendida e recolhida pela Polícia Militar de Meio Ambiente de Juiz de Fora, MG (1998-1999). Revista Brasileira de Zoociências, v. 8, n. 1, p. 23-33, 2006.

BORGES, L. A. C., RESENDE, J. L. P. 2007. Tutela Jurídica dos Recursos Faunísticos no Brasil. Curso de Pós-Graduação "Lato Sensu" (Especialização) a Distância. Universidade Federal de Lavras UFLA.

BRASIL. Decreto Federal n² 24.645, de 10 de julho de 1934. Disponível em <http://www6. senado.gov.br/legislacao/ListaPublicacoes.action?id=39567>. Acesso em: 10 mai 2011.

BRASIL. Lei Federal n 4.771 de 15 de setembro de 1965. Código Florestal Brasileiro. Disponível em <http://www.planalto.gov.br/ccivil_03/leis/L4771.htm>. Acesso em: 28 fev. 2012.

BRASIL. Lei Federal n 5.197 de 03 janeiro de 1967. Lei de proteção à fauna. Disponível em <http://www.planalto.gov.br/ccivil_03/Leis/L5197.htm>. Acesso em: 10 mai. 2011. 
BRASIL. Constituição da República Federativa do Brasil, de 1988. Disponível em <http://www. planalto.gov.br/ccivil_03/Constituicao/Constitui\%C3\%A7ao.htm>. Acesso em: 28 fev. 2012.

BRASIL. Lei Federal n 7.735, de 22 de fevereiro de 1989. Criação do IBAMA. Disponível em: <http://www.planalto.gov.br/ccivil_03/Leis/L7735.htm>. Acesso em: 10 mai. 2011.

BRASIL. Lei Federal no 9.605 de fevereiro de 1998. Nova Lei de Crimes Ambientais. Disponível em: <http://www.planalto.gov.br/ccivil_03/Leis/L9605.htm>. Acesso em: 10 mai. 2011.

BRASIL. Lei Federal no 9.985 de 18 de julho de 2000. Sistema Nacional de Unidades de Conservação. Disponível em: <http://www.planalto.gov.br/ccivil_03/Leis/L9985.htm>. Acesso em: 10 mai. 2011.

BRASIL. Decreto n 6.514 de 22 de julho de 2008. Disponível em: <http://www.planalto.gov.br/ ccivil_03/_Ato2007-2010/2008/Decreto/D6514.htm>. Acesso em: 10 mai. 2011.

BUCCI, R. L. F. et al. Legislação ambiental. Boletim Goiano de Geografia, v. 12, n. 1, p. 87-96, 1992.

CASTRO, E. B. V. et al. Ampliando a escala de conservação: avaliação de áreas potenciais e proposta de ampliação do Parque Nacional da Serra dos Órgãos, RJ. Revista Espaço \& Geografia, v. 11 , n. 1 , p. $115-145,2008$.

CARDOSO, H. F. Os animais e o direito: novos paradigmas. Revista Brasileira de Direito Animal, v. 2, n. 2, p. 115-147, 2007.

CULLEN JR., L.; BODMER, R. E.; VALADARES-PADUA, C. Effects of hunting in habitat fragments of the Atlantic Forests, Brazil. Biological Conservation, v. 95, n. 1, p. 49-56, ago. 2000.

Disponível em: <http://www.sciencedirect.com/science/article/pii/S0006320700000112>. Acesso em: 21 mai. 2013.

DELGADO, G. C. O setor de subsistência na Economia Brasileira: Gênese histórica e formas de reprodução. In: JACCOUD, L. Questão Social e Políticas Sociais no Brasil Contemporâneo. Brasília: IPEA, 2005.

DIAS, E. C. A Defesa dos Animais e as Conquistas Legislativas do Movimento de Proteção Animal do Brasil. Revista Brasileira de Direito Animal, v. 2, n. 2, p. 149-168, 2007.

DIXO, M. et al. Habitat fragmentation reduces genetic diversity and connectivity among toad populations in the Brazilian Atlantic Coastal Forest. Biological Conservation, v. 142, n. 8, p. 1560-1569, ago. 2009. Disponível em: <http://www.sciencedirect.com/science/article/pii/ S0006320708004540>. Acesso em: 21 mai. 2013.

IBAMA. Instituto Brasileiro do Meio Ambiente e dos Recursos Naturais Renováveis. Portaria ${ }^{\circ}$ 332 de 13 de março de 1990. Obtenção de licença para coleta de materiais zoológicos para fins científicos e didáticos. Disponível em <http://www.ibama.gov.br/fauna/legislacao/port_332_90. pdf >. Acesso em: 10 mai. 2011

IBAMA. Instituto Brasileiro do Meio Ambiente e dos Recursos Naturais Renováveis. Relatório Técnico Final Reserva de Fauna Baía de Babitonga. Brasília: IBAMA, 2007. 25 p. 
IBAMA. Instituto Brasileiro do Meio Ambiente e dos Recursos Naturais Renováveis. Instrução Normativa N¹54 de 01 de março de 2007. Institui o Sistema de Autorização e Informação em Biodiversidade - SISBio, na forma das diretrizes e condições. Disponível em < http://www4.icmbio. gov.br/sisbio/index.php?id_menu=210>. Acesso em: 23 fev. 2012.

LAURANCE, W. F. et al. The fate of Amazonian forest fragments: a 32-year investigation. Biological Conservation, v. 144, n. 1, p. 56-67, jan. 2011. Disponível em: <http://www.sciencedirect.com/ science/article/pii/S0006320710004209>. Acesso em: 21 mai. 2013.

LOURIVAL, R. F. F.; FONSECA, G. A. B. Análise de sustentabilidade do modelo de caça tradicional, no Pantanal da Nhecolândia, Corumbá, MS. In: VALLADARES-PADUA, C.; BODMER, R. E.; CULLEN JR., L. (Orgs). Manejo e conservação de vida silvestre no Brasil. Brasília: CNPq; Belém: Sociedade Civil Mamirauá, 1997, p. 123-172.

MYERS, N. et al. Biodiversity hotspots for conservation priorities. Nature, v. 403, p. 853-858, fev. 2000. Disponível em: <http://www.nature.com/nature/journal/v403/n6772/pdf/403853a0.pdf>. Acesso em: 21 mai. 2013.

MIRANDA, Leandro. Atletas do tiro detonam proibição da caça esportiva no Brasil. Terra Esportes, [s.I.], 13 out. 2011. Disponível em: < http://esportes.terra.com.br/jogos-pan-americanos/2011/ atletas-do-tiro-detonam-proibicao-da-caca-esportiva-no-brasil,3308447d660fd310VgnCLD20000 ObbccebOaRCRD.html>. Acesso em: 30 mar. 2012.

PAGANO, I. S. A. et al. Aves depositadas no Centro de Triagem de Animais Silvestres do IBAMA na Paraíba: uma amostra do tráfico de animais silvestres no estado. Ornithologia, v. 3, n. 2, p. 132144. 2009.

PERES, C. A. Effects of subsistence hunting on vertebrate community structure in Amazonian forests. Conservation Biology, v. 14, n. 1, p. 240-253, 2000. Disponível em: <http://onlinelibrary. wiley.com/doi/10.1046/j.1523-1739.2000.98485.x/full>. Acesso em: 21 mai. 2013.

PEZZUTI, J.; CHAVES, R. P. Etnografia e manejo de recursos naturais pelos índios Deni, Amazonas, Brasil. Acta Amazonica, v. 39, n. 1, p. 121-138, 2009.

PRIMACK, R. B.; RODRIGUES, E. Biologia da conservação. Londrina: Editora Vida, 2001.

ROMERO-MUÑOZ, A.; PÉREZ-ZUBIETA, J. C. Evaluación preliminar del comercio y uso de mamíferos silvestres en el mercado La Pampa de la ciudad de Cochabamba, Bolívia. Mastozoologia Neotropical, v. 15, n. 2, p. 253-259, 2008.

ROSAS, G. K. C.; DRUMOND, P. M. Caracterização da caça de subsistência em dois seringais localizados no estado do Acre (Amazônia, Brasil). Rio Branco, AC: Embrapa Acre, 2007. 31p. Disponível em: <http://ainfo.cnptia.embrapa.br/digital/bitstream/CPAF-AC/17290/1/doc109.pdf> . Acesso em: 21 mai. 2013.

SANTOS, A. A. Concessão ou terceirização de serviços turísticos em Parques Nacionais brasileiros: incentivo ao aumento de receitas. 2010. 280 p. Tese (Doutorado). Universidade Federal de Lavras, Lavras. 
TIBAU DO SUL. Decreto 14/2006. Criação da Reserva Faunística Costeira de Tibau do Sul. Disponível em: <http://pt.scribd.com/doc/19567151/decreto-refauts-0142006>. Acesso em: 10 mai. 2011.

TRF. Tribunal Regional Federal. Embargos infringentes em AC No 2004.71.00.021481-2/RS. 2008. Disponível em <http://www.trf4.jus.br/trf4/processos/visualizar_documento_gedpro.php?loc $\mathrm{al}=$ trf4\&documento $=2130570 \&$ hash $=1$ e5af6f45bbf991939481469̄e8a46b9a $>$. Acesso em: 28 fev. 2012.

UNESCO. Declaração de 27 de janeiro de 1978. Declaração Universal dos Direitos dos Animais. 1978. Disponível em: <http://www.forumnacional.com.br/declaracao_universal_dos_direitos_dos_ animais.pdf $>$. acesso em: 10 mai. 2011.

VIDOLIN, G. P. et al. Programa estadual de manejo de fauna silvestre apreendida - Estado do Paraná, Brasil. Caderno Biodiversidade, v. 4, n. 2, p. 37-49, 2004.

\section{Histórico editorial}

Recebido: 14/02/2013

Avaliação e copidesque: 27/02/2013 a 24/05/2013 